Forthcoming in Borch, C. and Wosnitzer, R. (eds.) (2018/19) Routledge Handbook to Critical Finance Studies. Abingdon: Routledge.

\title{
Beyond cynicism and fatalism: Three lessons for a social studies of financial regulation
} Nathan Coombs

Much like finance itself, critical thinkers tend to be suspicious of its regulation. Sometimes, it must be said, for good reason. After the near-collapse of the financial system in the 2007-8 crisis many inevitably asked: where were the central banks and securities authorities who were meant to be keeping us safe? 'Asleep at the wheel' was the kneejerk response of those frustrated by their inertia. Yet as it became clear that regulators not only failed to anticipate risks but had over the past decade ushered in many of the changes responsible for amplifying those risks, ${ }^{1}$ explanatory efforts shifted from the 'how' to the 'why'. Stigler's (1971) idea of regulatory capture, focused on the revolving door between financial firms and government, assumed a central role in making sense of the previous decade's deregulatory drive (Baker, 2010; Carpenter \& Moss, 2014; Johnson \& Kwak, 2010). Subtler forms of cultural, cognitive and intellectual capture were also proposed (Kang, 2014; Kwak, 2014). In these accounts, regulators didn't need to be dominated by the financial sector to betray the public interest; they were lulled into complacency by free-market orthodoxy and the veneration of efficient markets, rational expectations and the mathematical 'innovations' which it was believed had distributed risk safely throughout the financial system (Turner, 2009).

Other analyses, predominantly from policy-setting institutions, honed in on regulators' lack of knowledge. Failures of banking supervision, information gaps about derivatives markets, and a poor understanding of the endogenous instabilities of the financial system were presented as a problem of regulators hitting an epistemological impasse with the tools at their disposal (BCBS, 2009; IMF \& FSB, 2009). In the years since, attempts to break through the impasse have been multifaceted: from work by the new U.S. Office for Financial Research, to agent-based modelling of the financial system by central banks, to increased data collection by regulatory authorities. These knowledge augmentation efforts, often justified in reference to the post-crisis 'macroprudential' 
agenda (a concern with systemic risk in the financial system as a whole), have been recognised by scholars but without great enthusiasm. In part that is because many were expecting sweeping systemic changes in the wake of the crisis - and not just tools to increase regulatory vision. Those who have addressed regulators' new technologies have often been no less critical, focusing on the epistemological problems of governing complex and hyper-reflexive contemporary financial markets (Dorn, 2012a; Riles, 2013; Stellinga \& Mügge, 2017).

Even if motivated by a genuine desire to improve regulation, capture theoretic explanations for the crisis and critical commentary on attempts to improve regulatory knowledge are politically ambiguous. An unrelenting focus on regulators' susceptibility to capture, for instance, might breed cynicism and lead to the part played by agents pushing in the opposite direction being overlooked. Similarly, emphasis on the limited ability of central authorities to know enough about markets to control them can imply that anything short of (recentralised) financial repression requires relinquishing hope in governing (decentralised) twenty-first century finance. It is of course legitimate to argue that decomplexifying global finance should be regulators' goal (Engelen et al., 2012; Schneiberg \& Bartley, 2010), but fixed adherence to the position may encourage disinterest in the reforms that are being introduced and fatalism about their utility. Is there an alternative approach which might avoid these pitfalls? What would it mean to research and theorise financial regulation without either cynicism or fatalism?

This chapter argues that dispensing with these a priori theoretical prisms should be at the heart of the social studies of financial regulation. The pseudo-neologism takes its inspiration from the social studies of finance (SSF): a branch of economic sociology which since the early 2000s has applied the methodological tools of anthropology and science and technology studies to research on financial markets. With its roots in Michel Callon's (1998; Callon et al., 2007) ideas about how economics performs the economy, as well as the attention to 'non-human actors' licensed by actor-network theory (Latour, 2005; Law \& Hassard, 1999), SSF's distinctive methodological contribution concerns its attention to corporeal embodiment, technical infrastructures, and distributed cognition (MacKenzie, 2008, Chapter 2). In keeping with these foci, some of the field's famous studies include: the 'global microstructures' of screenbased trading (Knorr Cetina \& Bruegger, 2002); the performativity of the Black-Scholes options pricing formula (MacKenzie, 2006; MacKenzie \& Millo, 2003); the role of securitization in the credit crisis (MacKenzie, 2011; MacKenzie \& Spears, 2014b; 
Poon, 2009); and financial automation and high-frequency trading (MacKenzie et al., 2012; MacKenzie \& Pardo-Guerra, 2014; Borch \& Lange, 2017; MacKenzie, 2017). Regulation is never far away in this line of work, nor could it be given that financial products are 'synthetic bundles of law and measurement' (Black, 2013: 34 cited in Thiemann \& Lepoutre, 2017: 1776). Nevertheless, given the constitutive role of regulation in the evolution of markets, a number of authors have questioned why the field has not paid more attention to regulatory technologies (Coombs, 2016, 2017; Langley, 2015; Lenglet, 2011; Williams, 2009). The limited contact with wider debates about regulation in other parts of the academy could also be noted, whether that be ideational shifts (Baker, 2013; Blyth, 2002), structural power (Woll, 2016) or supervisory compliance strategies (Baldwin \& Black, 2008). Whatever the reasons for the absence of dialogue, this chapter argues that SSF can provide a sound methodological basis for interrogating financial regulation if adapted and tailored to the regulatory object of study. Below the proposed adaptations are distilled into three lessons, which provide a set of guiding methodological principles for a social studies of financial regulation building upon the field's science studies origins.

These lessons might strike readers as out-of-place in a volume dedicated to critical finance studies. If the take-home message of this chapter is the need to understand the motivations, tools and cultures of regulators and regulation before criticising their perceiving failings, does this not imply a less critical, or even acritical, approach? Some might draw that conclusion. Certainly, the social studies of finance has a history of frustrating critics with its reluctance to 'get political'. But as Borch and Howitzer (2018) put it convincingly in this volume's introduction, critique resting on conviction rather than a firm empirical basis is likely to prove a blunt instrument. Or, in Mehrling's (2017: 3) emphatic words: 'If we want change, we need to anchor our ideas in reality, which is to say in the logic that is expressed, in practice, in the [financial] system as it operates today'. Extending that insight to the regulatory sphere, it is not enough to speak about regulators' motivations, technologies and relationships with private-sector actors in terms of generalisations determined by political or social theories. Even limited engagement with regulators does much to dispel that idea that they are uniformly captured or labouring under the impression that their big data sets afford them omniscient knowledge. Indeed, one will find as much critique of regulatory practices from within regulatory community as in the academic literature. Paradoxically, then, the contention of this chapter is that by suspending some of the usual critical scholarly 
reflexes, at least temporarily, a social studies of financial regulation can not only discern instances of regulatory success but also tease out more powerful critiques of its failings and limitations.

\section{Lesson 1: Listen to the actors}

Bruno Latour's (2005) injunction to 'follow the actors' might not at first seem a promising basis for researching financial regulation. Methodological advice that has proven so productive in the laboratory setting, where the researcher is granted unfettered access to the social construction of scientific knowledge, has no obvious counterpart in the secretive worlds of central banking, securities regulation and transnational standard-setting. While there has been a drive over recent decades for regulators to make greater efforts at public engagement, the sensitivity of regulatory activities in the financial field limits the potential for ethnography and constrains the scope for frank exchanges in an interview setting. Unlike private-sector financial practitioners, who can be surprisingly open about divulging their practices, when pushed on their agenda regulators will usually defer to publically available policy documents.

Nevertheless, even if it not possible to follow the actors in a classically Latourian sense, approaching the regulatory field with a certain amount of epistemic humility will allow researchers to listen to the actors and appreciate the significance of what they do have the freedom to say. That is particularly the case in the post-crisis era in which the 'frontier quality' (Moloney et al., 2015: 2) of financial regulation presents researchers with an ideal opportunity for studying ideational innovation under conditions of extreme epistemic uncertainty. For researchers willing to shelve assumptions inherited from scholarly discourse and follow regulators into their own problem set, exploring the practical metaphysics of their work, there is therefore much to be gained by attempting to understand what it is that they are doing and attempting to achieve. Inhabiting that frontier space through full immersion the regulatory epistemic community will allow researchers to better appreciate the disconnections between the existing scholarly research and the aims, means and ends of regulatory practices.

To use an example from my own research (Coombs \& Morris, 2017), following the financial crisis stress testing emerged as one of key ways that regulators sought to improve the resilience of banks and their supervision. In contrast to the backward- 
looking, private-sector modelling practices that were important for determining the state of banks' balance sheets prior to the crisis, post-crisis regulatory stress tests involve the regulatory authority crafting a hypothetical macroeconomic crisis and asking the private banks to simulate how their balance sheets stand-up in the scenario. For example, regulators might craft a crisis scenario in which unemployment rises sharply, mortgage defaults increase, and share prices crash, with the aim to see if banks are capable of remaining solvent and supplying credit to the economy. What happens then varies depending upon the jurisdiction, but in the United States the consequences of poor performance can be severe. Failing the test runs not only reputational risks but can also result in sanctions where the Federal Reserve prevent banks from undertaking planned dividend payments or share buybacks.

Given that stress testing is one of regulators' most powerful levers of control over financial firms today, it is therefore surprising that the practice has attracted so little academic attention. Political economists, sensing a 'Minsky moment' with the postcrisis 'macroprudential ideational shift' (Baker, 2013), have catalogued the ways in which regulations have proven insufficiently counter-cyclical (Underhill, 2015). Langley (2013) sees in the crisis-era stress tests as a shift away from probabilistic risk governance towards anticipatory, enactment-based knowledge; but he has not explored the practice's continued role as an institutional fixture of post-crisis banking supervision. Policy literature fares little better. Goldstein's (2017) book, Banking's Final Test, while ostensibly about stress testing in fact focuses on how capital is measured in the baseline, non-stressed scenario. The result is a significant lacuna in the scholarship. What stress testing is seeking to achieve, what knowledge the exercise furnishes, and what changes it is effecting are questions yet to be posed satisfactorily. Is stress testing a form of anticipatory governance? Or is it about reforming banks' risk management and organizational cultures? Or is it simply about driving higher capitalization across the banking sector? It is this lesson's contention that a good first step towards answering these questions would be to ask the regulators and firms implementing the tests - and listen attentively to their answers.

Another example. As documented by a string of high-profile exposes in the popular press (Lewis, 2014; Patterson, 2012), financial markets have become increasingly automated since the early 1990s. With the collocation of trading firms' servers next to exchanges' data centres, the use of short but sophisticated arbitrage algorithms, and the development of high-speed communications networks, trading has accelerated 
towards sub perceptual milli- and micro-second speeds. In recent years a nascent sociological literature has emerged on this high-frequency trading (HFT). Its historical sociology, the subjectivity and emotions of HF traders, and the material political economy of the technical infrastructure have all proven productive areas of research (Borch \& Lange, 2017; MacKenzie, 2017; MacKenzie \& Pardo-Guerra, 2014). Inevitably, given concerns prompted by events such as the 2010 'Flash Crash' (in which algorithmic trading was implicated in the Dow Jones crashing by $9 \%$ in a matter of minutes) there has also been much interest in the HFT's regulatory implications, generally from one of two interconnected angles. First is concern with speed. Does the velocity of HFT pose hitherto unprecedented challenges for security market governance (Angel, 2014; Thompson, 2016)? Second is interest in the consequences of automation. Does the fact that it is now algorithms executing the majority of trades mean that it is necessary to rethink the current regulatory regime's human-centric conception of agency (Kirilenko \& Lo, 2013; Lenglet, 2011)?

These are important questions. However, here again it is necessary to contrast scholarly reflections with actual policies and practices. For when one examines regulations directed at automated trading, ${ }^{2}$ their emphases are more prosaic; the focus is on improving the testing of automated trading systems and providing trade surveillance departments with better means to monitor the market. Indeed, when I conducted research on the German High-Frequency Trading Act the regulators I spoke to dismissed speed or post-human agency as having anything to do with the Act's motivations (Coombs, 2016). The Act's requirement that trading firms label (tag) their algorithms with a numerical code was instead a response to the difficulties trade surveillance officers were experiencing in interpreting market events with only trader IDs to identify the different strategies at play. These practical concerns made the implementation of the Act's algorithm-tagging rule no less vexed, though. The rule's novelty required regulators to pose acutely philosophical problems: What individuates an algorithm? Where does one algorithm begin and another stop? Should an algorithm be defined with respect to code or its strategy?

How regulators answered these questions by building upon the expertise of market participants ultimately proved a case study in 'meta-regulation' (Gilad, 2010) rather than speaking directly to scholars' concerns about the movement into the algorithmic age. The disconnect is, to some extent, inevitable. As argued by Ziewitz (2016), as a result of growing interest in algorithms across the humanities and social sciences, 
'algorithm' has come to function as a 'figure' or 'sensitizing concept', channelling diverse concerns about computation, automation and control. Indeterminacy is not necessarily a problem; polyvalent concepts can be productive; they allow academics to pose the big questions that might otherwise get lost in the minutiae of concrete practices. What the social studies of financial regulation can do, by listening to how regulators are tackling problems pragmatically, is provide conceptual regulation to such discussions and reign in their speculative excesses.

To be clear, this lesson's suggestion to listen to regulatory actors does not just mean to interview them in person (even if desirable). Listening can be as mundane an act as reading, in an unprejudiced way, their reports, speeches, and analyses. For if one approaches regulation with the attitude sometimes found in political economy or critical sociology, convinced that regulators are failing and determined to find out why, then the answers to the inquiry will likely be pre-determined by the questions. Neither is disdain for 'technocrats' conducive to understanding their motivations and operational constraints. There is a beautiful passage in Annelise Riles's (2011) book, Collateral Knowledge, which sends a countervailing message to those who would cast technocrats as little more than the shadowy vehicles for elite conspiracies. She recalls discussions with a systems-builder at the Bank of Japan developing a real-time settlement system for derivatives trades in the late 1990s. Although the system unwound prior regulatory interventions and curbed the central bank's role in economic coordination, it was not conceived by the actors involved in the project as neoliberal capitulation. Rather, giving the banks what they wanted, in the historical context of the time, was invested with a utopian spirit of improvement and modernization. Riles reflects poignantly on the political ambivalence and imaginative subjectivity of the technocratic spirit:

Technocratic thought goes hand in hand with dreams: dreaming is an act setting itself apart from the world as it is lived today. It is a small-scale, personal utopianism, predicated on a distance between the world as other see it and the world as it could be. (Riles, 2011: 140)

It is, I propose, the task of researchers to take seriously these small acts of dreaming and utopian vision. By its nature, financial regulation is rarely a transformative project. More often than not, its technocratic remit precludes the grand ambitions which excite sociologists and political economists. This lesson's call to listen to the regulators actors means to make attempts at closing that gap; to learn to appreciate the incremental 
improvements regulators are seeking, and evaluating their successes or failures on those terms.

\section{Lesson 2: Models matter}

The second lesson will be familiar to those who have followed the development of SSF since the early 2000s. An innovation of the field has been to encourage focus on the mathematical models and technical details of financial practices, breaking down the division of labour between financial economics and the (broader) social sciences. From the tradition's pragmatist perspective, modelling is seen not as aiming for objective truth, but rather as a cultural practice aiming to generate useful results (Millo \& MacKenzie, 2009), to provoke 'reality as effectuation' (Muniesa, 2014: 16). Callon (1998) is widely credited with setting in motion this strand of thought when he theorised how economics, in the act of measurement, does not represent the economy but remakes it in its image. MacKenzie and Millo's (2003) study of the Black-ScholesMerton (BSM) option pricing formula takes the insight a step further. Arguing that Callon's understanding of performativity assumed a frictionless account of how economic measurement effectuates economic change, MacKenzie and Millo instead show the contingent, cultural work by traders on the Chicago Board Options Exchange necessary for the BSM model's predictions to converge with actual market prices. Thus, their study demonstrates not that models have intrinsically transformative powers but rather that the conversion of ideas into material practices is a fragile process. For every model's success, there is a model that fails to realise its theoretical promise.

Other investigations which demonstrate the fruitfulness of a technical orientation focus on the 2007-9 financial crisis. In contrast to popular representations of the crisis as the result of a private-sector run rampant, a common theme of sociological scholarship is to stress the unintended consequences of the US government's efforts to extend credit for home ownership after the Great Depression (Poon, 2009). Even the instrument so centrally involved in the crisis, the 'mortgage-backed security' (MBS) where a pool of mortgage loans are packaged into a bond paying a fixed income to investors - emerged in the 1970s to help fund new mortgages through the government-sponsored enterprises, Fannie Mae and Freddie Mac. Fligstein and Goldstein $(2010,2017)$ show that while in its initial stages the introduction of MBS 
encouraged fragmentation in the mortgage market with the infamous 'originate to distribute' model, by the 2000s banks began to vertically integrate the securitization value chain in order to capture its lucrative fees. Major US banks became heavily invested in issuing loans for new mortgages, securitizing and selling those loans, and also retaining a significant number for themselves. Due to pressure to keep the supplychain fed with new loans for mortgage securitization, from 2003 banks moved into the 'non-conventional' mortgage market: namely, subprime and non-conforming loans. The collateralised debt obligation (CDO), an instrument structurally similar to MBS but with its origins in corporate loan market, played a crucial role in feeding the machine by enabling the repackaging risky BBB-rated MBS tranches into apparently safe AAA-rated MBS-CDO (a CDO with MBS as its underlying assets).

MacKenzie's (2011) study complements this scholarship by putting under a microscope the models used to financially engineer MBS-CDO and explaining how they could have caused so much damage without assuming coordinated malfeasance in the financial sector. In contrast to Fligstein and Goldstein's focus on industrial control within firms, Mackenzie's explanatory focus rests with the 'clusters of evaluation practices' (MacKenzie, 2011: 1782) or 'evaluation cultures' (MacKenzie \& Spears, 2014b: 395) spanning across different banks and credit rating agencies. At the centre of the story is the emergence of the parallel evaluation culture in the 1990s for assessing the risk of CDO. Driven by advances in mathematical modelling, CDO, unlike MBS, were evaluated using the family of Gaussian copula models designed to quantify the correlation in the risk of default of the underlying asset pool. On MacKenzie's account, it was the independent evaluation cultures of MBS and CDO, and their eventual combination in the MBS-CDO, that led to arbitrage opportunities being exploited systematically and risks heightened. However, as MacKenzie and Spears (2014a) note, this does not mean that CDO quants employed Gaussian copula models in ignorance of their limitations; some were sceptical about them from the beginning. What emerges is a sense of the power and opacity-generating properties of financial models without reducing their users to 'model dopes' (MacKenzie \& Spears, 2014a: 419; see also Beunza \& Stark, 2012; Svetlova, 2012). Models provide a useful communicative and calculative medium that cuts across institutions, but can also prove dangerous by creating homogeneous cultural and organizational blind spots that leads to risks being overlooked. 
For researchers sympathetic to SSF, it should thus be clear that models matter. The point of this lesson is that bringing these sensibilities to bear in studying the regulatory sphere holds untapped potential for opening up new avenues for social scientific analysis. A brief survey of the existing literature will help explain why. Within political science, work on regulation has historically operated at a high level of abstraction from the details of regulatory practices. The focus of has been on the shifting balance of power between states; the role played by transnational technical networks; and the tension between global soft-law and state sovereignty (Helleiner \& Pagliari, 2011; Young, 2014). In the limited sociological work on financial regulation, the public/private dichotomy has done much of the equivalent heavy-lifting. Public regulation is associated with state control and some degree of (at least potential) democratic determination; private regulation, by contrast, is associated with a selfregulatory regime which precludes democratic determination of the decision-making process (Carruthers, 2015; Dorn, 2012b, 2015, 2016). Insofar as insistence on the distinction between public and private is a response to fuzzy theorisation of multi-level governance that became so popular in the 1990s, it serves as a necessary corrective for placing control back at the centre of the scholarly analysis. On the other hand, it is in danger of missing the significance of the emergence of the Black-Scholes world of financial risk management (Millo \& MacKenzie, 2009; Coombs \& van der Heide, 2019). In the same way that MacKenzie's notion of 'evaluation cultures' draws attention to practices that cut across financial institutions, so too does it point to the limits of an understanding of financial governance divided into discrete public and private spheres.

The best example is provided by the evolution of international capital regulation. In brief, a bank's capital is the size of its assets (such as its loans) minus its liabilities (such the debt it takes on to fund those loans). The capital ratio, perhaps the most important metric in banking regulation, is a measure of the quality of this capital. It places secure capital (such as a bank's retained earnings) on the numerator, and divides that by the risk sensitive capital (such as the bank's loans) in the denominator. The idea is that the higher a bank's capital ratio is the more resilient it will be to loan defaults or adverse market movements during an economic crisis (the most accessible introduction to the subject is Admati \& Hellwig, 2013).

The origins of the Basel Accord, the first international bank capital standard, go back to the early 1980s. The desire for a global definition of capital and capital ratio standard was motivated by a perceived global decline in bank capital at the time (Goodhart, 
2011: Chapter 6). The result of a tortuous negotiating process between states and their central banks, the 1988 Accord, Basel 1, eventually settled upon an 8\% capital to risk-weighted assets standard and a risk bucket methodology assigning different types of credit risk to a limited number of categories. For example, sovereign bonds were awarded a risk weight of $0 \%$, whereas equities received a weight of $100 \%$. Going into the 1990s, the Basel Committee then began work on expanding capital requirements to include interest rate risk and market risk. Impressed with the modelling going on in banks, grounded in academic financial theory, the expansion of the standards culminated in the 1997 Market Risk Amendments which allowed banks to utilize their internal Value-at-Risk (VaR) models for determining the regulatory capital necessary to cover the risk in their trading book. Basel II went further with the introduction of an advanced internal ratings-based approach (A-IRB) allowing banks to also calculate the regulatory capital needed to cover their credit risk. The discretion this afforded to banks' risk managers is widely credited with encouraging the decline in bank capitalisation in the run up to the 2007-9 financial crisis. In its aftermath, Basel III, agreed upon in 2010-11, responded with increased capital ratio requirements, stricter definitions of capital, and counter-cyclical provisions.

There are a number of ways to analyse the policy evolution. A political economy approach would be to refract the events through the prism of great power rivalry: an interpretation with clear saliency in the run-up to the first Basel Accord. ${ }^{3} \mathrm{~A}$ sociological approach, by contrast, would see a shifting balance between public and private actors, with Basel I as public-private regulation, Basel II as private-public regulation, and Basel III as an ambiguous move back towards public-private regulation. A social studies of financial regulation might however take an alternative approach. This would involve tracing the role played by the 'no-arbitrage' evaluation culture (MacKenzie and Spears, 2014a) in shaping the internal modelling provisions of the Market Risk Amendment and Basel II. With close attention to the historical sociology of these modelling practices, the approach could trace the practices' micro-sociological and material dynamics and how they cut across and ideationally infused both public and private spheres. The aim is to see how risk management, and its attendant technologies, ended up exerting its own dynamics and path dependencies in financial regulation (for an example of such an analysis see Lockwood, 2015).

If the idea of evaluation cultures can shed light on the policy evolution, it remains less clear if performativity is an appropriate concept through which to analyse regulation. 
After all, regulatory models are explicitly prescriptive and to say that when they are implemented they have performed their function is not to say anything that could not be said with simpler language. One way in which the idea of performativity might prove more directly relevant is in analysing the unintended consequences of regulatory interventions. For example, I have argued that although the German HFT Act's algorithm-tagging rule was intended primarily to help trade surveillance departments, the rule's implementation also encouraged beneficial cultural changes within trading firms through opening up their algorithmic black boxes to internal scrutiny (Coombs, 2016). That, however, is just one example. How plentiful such instances of regulatory performativity are, and how substantial the changes they effect prove over the medium to long term, remains to be seen.

In sum, a social studies of financial regulation recognises that models matter. The models addressed in this lesson derive from the Black-Scholes genealogy of risk management which the majority of work in SSF focuses on, but 'model' in the regulatory domain can be interpreted in a more catholic sense. Even the original Basel I risk bucket methodology was a model of sorts, albeit one at odds with the computationally complex form of modelling pioneered in banks. And yet, such research should not stop at recognising that models matter. By drilling down into their fine details it should seek to interrogate their origins, the problems they are addressing, and the effects they have. How to do so is the subject of lesson 3, to which we now turn.

\section{Lesson 3: Discover the macro in the micro}

The question of the link between the micro and the macro has theoretical antecedents dating as far back as classical philosophy and metaphysics (Alexander \& Giesen, 1987). Within sociology, the micro-macro divide has typically pivoted on whether the structural constraints of society, institutions and economic systems are decisive, or whether individual or small group acts of interaction, interpretation and sense-making should be the focus for empirical investigation. There have been countless attempts at synthesising these perspectives, but actor-network theory (ANT) has arguably championed the most radical perspective by arguing that there is no way that we can know 'a priori that macro-actors are bigger than or superior to micro-actors' (Callon \& Latour, 2015: 280). ANT questions the assumption that the designations 'macro' or 
'micro' map on to objectively larger or smaller units of analysis, with different methodological tools being appropriate to address them. As an alternative, it proposes that both 'levels' are the result unstable translations that researchers need to map out. The implication for the study of financial markets, according to MacKenzie (2008: 33), is we should be suspicious of fixed scales of analysis dividing up small, 'micro' phenomena such as technical devices and interpersonal interactions from large, 'macro' phenomena such as capitalism, globalization, and so on. The interest lies in instances where the former becomes decisive for the latter, and vice versa.

Knorr Cetina and Bruegger (2002) have made the most straightforward application of this approach in their theorisation of foreign exchange (FX) markets as 'global microstructures' in which 'face-to-screen' interaction and 'response-presence-based conversation' sustain the transnational order. In contrast to economic sociology's tendency to theorise away the specificities of market types, they argue that the nonintermediary trading culture of FX markets lessens the significance of organizations in their coordination. Instead, understanding these markets requires attention to the part played by individual traders who are granted freedom to take positions depending upon their own judgement. The shift in emphasis not only directs attention to traders' screen-based coordination activities, but can also, Knorr Cetina and Bruegger claim, explain the readiness of banks' to locate their operations in global financial centres rather than remaining close to production centres. A 'small' micro observation about the idiosyncrasies of market coordination speaks to a 'large' macro question about financial geography.

Another study that bridges the micro-macro divide is MacKenzie's (2011) aforementioned analysis of the global financial crisis. To recall, this locates a contributing factor in the divergent evaluation cultures of MBS and CDO which allowed the benefits of diversification to be illegitimately reaped twice in the construction of MBS-CDO. One of MacKenzie's most provocative claims - provocative because some have argued that it depoliticises the financial crisis by reducing it to a technical error (Engelen et al., 2011) - is that in extending the use of CDO from corporate loans to mortgages a lack of historical data, and a desire to maintain consistency with existing practices, led to a correlation factor of 0.3 being arbitrarily adopted. The choice was a fateful one, since if banks and credit rating agencies had opted for a higher correlation of, for example 0.8 , then it would not have been possible to construct profitable arbitrage CDO. Thus is a seemingly innocuous technical decision invested with salience 
for understanding the roots of the credit crisis. Yet as MacKenzie stresses, his micro finding is not a substitute for macro analyses; it is intended to complement them by drawing attention to how the technical substratum bisects the systemic dimensions of the crisis.

If the idea of discovering the macro in the micro is firmly enshrined in SSF, how might such an approach be extended to financial regulation? There are at least two potential ways. The first concerns the history of classification. As the rich science studies literature on standards and their stories has shown, seemingly slight definitional and classification issues are important objects of analysis in the history of knowledge (Bowker \& Star, 1999). Some of the best work in the field focuses on cases of biological classification and their large effects on institutional structures, funding mechanisms, and discursive constructions that build up around the contested 'object'. For example, viruses have proven persistently difficult objects to classify, falling between the cracks of life and non-life, hence have led to institutional impediments to scientific progress in this area.

In finance, classification dilemmas for regulators can have similarly large-scale effects. One striking example is recent work on the historical sociology of HFT. Seeking to account for how it is possible that HF algorithms can predict prices, Mackenzie (forthcoming) identifies an important predictive signal transmitted between the Chicago futures markets and stock trading in New York. The 'futures lead' arises because regulatory rules governing futures trading allow greater leverage than with equities. MacKenzie traces the origins of the divergent rules to the creation of the Commodity Futures Trading Commission (CFTC) in 1974. The addition of 'twenty carefully-chosen words to the long list of commodities' determining the agency's mandate - namely 'and all services, rights, and interests in which contracts for future delivery are presently or in the future dealt in' - was decisive for creating a permanent jurisdictional demarcation between the CFTC and the Securities and Exchange Commission. This historically contingent 'micro' feature of the agencies' remits and their differing rules on leverage led to the futures lead, with that signal, in turn, being responsible the establishment of a vast technological infrastructure of fibre optic cables and microwave paths for HFT between Chicago and New York.

A study by Funk and Hirschman (2014) further underlines the importance of such categorical regulatory distinctions. By tracing the history of interest rate and foreign exchange swaps from the early 1980s, they argue that financial innovations create 
problems for regulators and opportunities for private sector firms. Because regulators use categories to 'filter and make sense of the people, organizations, and products they oversee' (Funk \& Hirschman, 2014: 670), innovations that do not fit into those categories can be deeply destabilising. Other studies have shown how market actors actively lobby against the classification of their products so at to evade regulation (Weiss \& Huault, 2016).

Of course, regulation does not begin and end with the decisions of public actors. A second way to discover the macro in the micro concerns how regulatory rules and models are implemented by the firms themselves. Here, there is an excellent opportunity to explore the under-documented interpretative work of compliance officers and its consequences. Compliance officers have an organizationally ambiguous role, being on the payroll of firms but tasked with the para-regulatory function of ensuring that their firm upholds the rules. That task is often far from straightforward (Lenglet, 2012). With the details of rules often left indeterminate, compliance officers have to exercise creative discretion in determining how regulatory 'rules and models are reshaped during their implementation' (Schneiberg \& Bartley, 2008: 49). For example, in the implementation of the German HFT Act, it was the way that the 'parameter' of an algorithm was left undefined that opened the door to a multiplicity of interpretations by different trading firms: with the result being that some firms were tagging only a handful of algorithms, and other labelling thousands per year (Coombs, 2016). Such findings can potentially speak to unresolved epistemological questions about the capacities of regulatory knowledge. The imperative to discover the macro in the micro is therefore as much about informing high-level theoretical debates as it is about charting the historical pathways by which regulation has shaped the evolution of markets.

Like the preceding lessons, this lesson follows SSF along its well-established science studies path. Yet, while such an approach has harboured potential for a long time, the it is leant particularly urgency following the financial crisis. For if there is one significant change which begins with the regulatory response to the crisis it is the proliferation of regulatory models and new fine-grained rules. It is this lesson's contention that it is necessary to examine the motivations, sociotechnical constructions and implementation of these models to arrive at a judicious view of the state of art of financial regulation. 


\section{Conclusion: Avoid micro-tribalism}

Scholarship on financial regulation is, in some senses, still in its infancy. The theoretical prisms this chapter has taken exception to - capture theory and critical commentary on regulation's epistemic limits - are not so much wrong as lacking a firm enough basis in fine-grained empirical research. It is almost certain that some regulators in some institutions have been captured at some points in time. It is the task of researchers to discover the temporal shifts and institutional diversity of the phenomenon. Likewise, it is certainly the case that there are epistemological challenges to governing financial markets; indeed, one could argue that financial regulation is today increasingly focused on pushing back against existing knowledge limits. There is a place for high-level reflections on the epistemological problems of regulation, whether drawing on the work of Friedrich Hayek or more recent sociological work on performativity, reactivity and market reflexivity. However, as argued in this chapter, it is at some point necessary to descent from the lofty heights of philosophy into the situated social practices in which regulatory knowledge is constructed, often in tandem with financial firms themselves. Listening to the actors, attending to their models, and discerning the micro in the macro represent three crucial lessons which might help researchers break free from the critical doom loop of cynicism and fatalism. A final question is: who should be applying the above principles? Obviously, since the social studies of financial regulation is a part of SSF, its natural disciplinary home is sociology. However, it is also true that in the last decade there has been a blossoming of interdisciplinary International Political Economy which has, to some extent, absorbed from SSF the idea of attending to the details of finance through fine-grained empirical work. As a consequence, today there is no need for a new academic 'microtribe' (Alvesson et al., 2017). Any discipline or field can embrace the above principles. And indeed they should. An uncharted frontier awaits.

\section{References}

Admati, A., \& Hellwig, M. (2013). The Bankers' New Clothes. Princeton and Oxford: Princeton University Press. 
Alexander, J. C., \& Giesen, B. (1987). From Reduction to Linkage: The Long View of the Micro-Macro Debate. In J. C. Alexander, B. Giesen, R. Munch, \& N. J. Smelser (Eds.), The Micro-Macro Link (pp. 1-42). Berkeley, CA: University of California Press.

Alvesson, M., Gabriel, Y., \& Paulsen, R. (2017). Return to Meaning: A Social Science with Something to Say. New York, NY: Oxford University Press.

Angel, J. J. (2014). When Finance Meets Physics: The Impact of the Speed of Light on Financial Markets and Their Regulation. Financial Review, 49(2), 271-281.

Baker, A. (2010). Restraining regulatory capture? Anglo-America, crisis politics and trajectories of change in global financial governance. International Affairs, 86(3), 647663.

Baker, A. (2013). The New Political Economy of the Macroprudential Ideational Shift. New Political Economy, 18(1), 112-139.

Baldwin, R., \& Black, J. (2008). Really Responsive Regulation. The Modern Law Review, 71(1), 59-94.

Basel Committee on Banking Supervision (BCBS). (2009). Principles for sound stress testing practices and supervision. Bank for International Settlements.

Beunza, D., \& Stark, D. (2012). From dissonance to resonance: cognitive interdependence in quantitative finance. Economy and Society, 41(3), 383-417. Blyth, M. (2002). Great Transformations: Economic Ideas and Institutional Change in the Twentieth Century. Cambridge: Cambridge University Press.

Borch, C., \& Lange, A.-C. (2017). High-frequency trader subjectivity: emotional attachment and discipline in an era of algorithms. Socio-Economic Review, 15(2), 283-306.

Bowker, G. C., \& Star, S. L. (1999). Sorting Things Out: Classification and its Consequences. Cambridge, MA: MIT Press.

Callon, M. (1998). Introduction: The embeddedness of economic markets within economic theory. In M. Callon (Ed.), The Laws of the Markets. Oxford and Malden, MA: Blackwell Publishers.

Callon, M., \& Latour, B. (2015). Unscrewing the big Leviathan: how actors macrostructure reality and how sociologists help them to do so. In K. Knorr-Cetina \& A. V. 
Cicourel (Eds.), Advances in social theory and methodology: Toward an integration of micro- and macro-sociologies (pp. 277-303). London and New York: Routledge.

Callon, M., MacKenzie, D., Muniesa, F., \& Sui, L. (Eds.). (2007). What Does It Mean to Say That Economics is Performative? In Do Economists Make Markets? On the Performativity of Economics (pp. 311-357). Princeton and Oxford: Princeton University Press.

Carpenter, D. P., \& Moss, D. A. (2014). Preventing regulatory capture: special interest influence and how to limit it. New York: Cambridge University Press, 2014.

Carruthers, B. G. (2015). Economy and Law: Old Paradigms and New Markets. In N. Dodd \& P. Aspers (Eds.), Re-Imagining Economic Sociology (pp. 127-146). Oxford: Oxford University Press.

Coombs, N. (2016). What is an algorithm? Financial regulation in the era of highfrequency trading. Economy and Society, 45(2), 278-302.

Coombs, N. (2017). Macroprudential versus monetary blueprints for financial reform. Journal of Cultural Economy, 10(2), 207-216.

Coombs, N., \& Morris, J. H. (2017). Narrating imagined crises: Stress tests, post-crisis regulation, and cultural reform in banking. Retrieved from https://osf.io/preprints/socarxiv/jzt4m

Coombs, N. \& van der Heide, A. (2019). Materialising financialization: How finance became financialized. In Mader, P., Mertens, D. and van der Zwan, N. (eds.) International Handbook of Financialization. Abingdon: Routledge

Dorn, N. (2012a). Knowing markets: would less be more? Economy and Society, 41(3), 316-334.

Dorn, N. (2012b). Render Unto Caesar: EU Financial Market Regulation Meets Political Accountability. Journal of European Integration, 34(3), 205-221.

Dorn, N. (2015). Democracy and Diversity in Financial Market Education. Abingdon: Routledge.

Dorn, N. (2016). Introduction: questions asked. In N. Dorn (Ed.), Controlling Capital: Public and Private Regulation of Financial Markets (pp. 1-18). Abingdon: Routledge. 
Engelen, E., Erturk, I., Froud, J., Johal, S., Leaver, A., Moran, M., ... Williams, K. (2011). After the Great Complacence: Financial Crisis and the Politics of Reform. Oxford: Oxford University Press.

Engelen, E., Ertürk, I., Froud, J., Johal, S., Leaver, A., Moran, M., \& Williams, K. (2012). Misrule of experts? The financial crisis as elite debacle. Economy and Society, 41(3), 360-382.

Fligstein, N., \& Goldstein, A. (2010). The Anatomy of the Mortgage Securitization Crisis. In M. Lounsbury \& P. M. Hirsch (Eds.), Markets on Trial: The Economic Sociology of the U.S. Financial Crisis (pp. 27-68). Bingley, UK: Emerald Group Publishing.

Funk, R. J., \& Hirschman, D. (2014). Derivatives and Deregulation Financial Innovation and the Demise of Glass-Steagall. Administrative Science Quarterly, 59(4), 669-704.

Gilad, S. (2010). It runs in the family: Meta-regulation and its siblings. Regulation \& Governance, 4(4), 485-506.

Goldstein, A., \& Fligstein, N. (2017). Financial markets as production markets: the industrial roots of the mortgage meltdown. Socio-Economic Review, 15(3), 483-510.

Goldstein, M. (2017). Banking’s Final Exam: Stress Testing and Bank-Capital Reform. Washington, DC: Peterson Instiute for International Economics.

Goodhart, C. (2011). The Basel Committee on Banking Supervision: A History of the Early Years 1974-1997. Cambridge: Cambridge University Press.

Helleiner, E., \& Pagliari, S. (2011). The End of an Era in International Financial Regulation? A Postcrisis Research Agenda. International Organization, (1), 169. International Monetary Fund (IMF), \& Financial Stability Board (FSB). (2009). The Financial Crisis and Information Gaps: Report to the G-20 Finance Ministers and Central Bank Governors. Retrieved from https://www.imf.org/external/np/g20/pdf/102909.pdf Johnson, S., \& Kwak, J. (2010). 13 bankers: the Wall Street takeover and the next financial meltdown (First edition.). New York: Pantheon Books.

Kang, M. (2014). The politics of bank bailout in Japan: a cognitive capture and leadership view. The Pacific Review, 27(2), 193-215. 
Kirilenko, A. A., \& Lo, A. W. (2013). Moore's Law versus Murphy's Law: Algorithmic Trading and Its Discontents. The Journal of Economic Perspectives, 27(2), 51-72.

Knorr Cetina, K., \& Bruegger, U. (2002). Global Microstructures: The Virtual Societies of Financial Markets. American Journal of Sociology, 107(4), 905-950.

Kwak, J. (2014). Cultural Capture and the Financial Crisis. In D. Carpenter \& D. A. Moss (Eds.), Preventing Regulatory Capture: Special Interest Influence and How to Limit It (pp. 71-98). New York: Cambridge University Press.

Langley, P. (2013). Anticipating uncertainty, reviving risk? On the stress testing of finance in crisis. Economy and Society, 42(1), 51-73.

Langley, P. (2015). Liquidity lost: the governance of the global financial crisis. Oxford: Oxford University Press.

Latour, B. (2005). Reassembling the Social: An Introduction to Actor-Network Theory. Oxford: Oxford University Press.

Law, J., \& Hassard, J. (1999). Actor Network Theory and After. Wiley.

Lenglet, M. (2011). Conflicting Codes and Codings: How Algorithmic Trading Is Reshaping Financial Regulation. Theory, Culture \& Society, 28(6), 44-66.

Lenglet, M. (2012). Ambivalence and Ambiguity: The Interpretative Role of Compliance Officers. In I. Huault \& C. Richard (Eds.), Finance: The Discreet Regulator: How Financial Activities Shape and Transform the World (pp. 59-84). Houndmills: Palgrave Macmillan.

Lewis, M. (2014). Flash Boys: Cracking the Money Code. London: Allen Lane.

Lockwood, E. (2015). Predicting the unpredictable: Value-at-risk, performativity, and the politics of financial uncertainty. Review of International Political Economy, 22(4), $719-756$.

MacKenzie, D. (forthcoming). Material Signals: A Historical Sociology of High-Frequency Trading. American Journal of Sociology.

MacKenzie, D. (2006). An Engine, Not a Camera: How Financial Models Shape Markets. Cambridge, MA: MIT Press. 
Mackenzie, D. (2008). Material Markets: How Economic Agents are Constructed. Oxford: Oxford University Press.

MacKenzie, D. (2011). The Credit Crisis as a Problem in the Sociology of Knowledge. American Journal of Sociology, 116(6), 1778-1841.

MacKenzie, D. (2017). A material political economy: Automated Trading Desk and price prediction in high-frequency trading. Social Studies of Science, 47(2), 172-194.

MacKenzie, D., Beunza, D., Millo, Y., \& Pardo-Guerra, J. P. (2012). Drilling Through the Allegheny Mountains. Journal of Cultural Economy, 5(3), 279-296.

MacKenzie, D., \& Millo, Y. (2003). Constructing a Market, Performing Theory: The Historical Sociology of a Financial Derivatives Exchange. American Journal of Sociology, 109(1), 107-145.

MacKenzie, D., \& Pardo-Guerra, J. P. (2014). Insurgent capitalism: Island, bricolage and the re-making of finance. Economy and Society, 43(2), 153-182.

Mackenzie, D., \& Spears, T. (2014a). 'A device for being able to book P\&L': The organizational embedding of the Gaussian copula. Social Studies of Science, 44(3), $418-$

Mackenzie, D., \& Spears, T. (2014b). 'The formula that killed Wall Street': The Gaussian copula and modelling practices in investment banking. Social Studies of Science, 44(3), 393-417.

Millo, Y., \& MacKenzie, D. (2009). The usefulness of inaccurate models: Towards an understanding of the emergence of financial risk management. Accounting, Organizations and Society, 34(5), 638-653.

Moloney, N., Ferran, E., \& Payne, J. (2015). Introduction. In N. Moloney, E. Ferran, \& J. Payne (Eds.), The Oxford Handbook of Financial Regulation (2nd ed., pp. 1-10). Oxford: Oxford University Press.

Muniesa, F. (2014). The Provoked Economy: Economic Reality and the Performative Turn. London: Routledge.

Patterson, S. (2012). Dark Pools: The Rise of A. I. Trading Machines and the Looming Threat to Wall Street. Random House. 
Poon, M. (2009). From new deal institutions to capital markets: Commercial consumer risk scores and the making of subprime mortgage finance. Accounting, Organizations and Society, 34(5), 654-674.

Riles, A. (2011). Collateral Knowledge: Legal Reasoning in the Global Financial Markets. Chicago and London: The University of Chicago Press.

Riles, A. (2013). Market collaboration: finance, culture, and ethnography after neoliberalism. American Anthropologist, 115(4), 555-569.

Schneiberg, M., \& Bartley, T. (2008). Organizations, Regulation, and Economic Behavior: Regulatory Dynamics and Forms from the Nineteenth to Twenty-First Century. Annual Review of Law and Social Science, 4(1), 31-61.

Schneiberg, M., \& Bartley, T. (2010). Regulating or Redesigning Finance? Market Architectures, Normal Accidents, and Dilemmas of Regulatory Reform. In M. Lounsbury \& P. M. Hirsch (Eds.), Markets on Trial: The Economic Sociology of the U.S Financial Crisis (Vol. 30, pp. 279-305). Bingley, UK: Emerald Group Publishing.

Stellinga, B., \& Mügge, D. (2017). The regulator's conundrum. How market reflexivity limits fundamental financial reform. Review of International Political Economy, O(0), 131.

Stigler, G. J. (1971). The Theory of Economic Regulation. The Bell Journal of Economics and Management Science, 2(1), 3-21.

Svetlova, E. (2012). On the performative power of financial models. Economy and Society, 41(3), 418-434.

Thiemann, M. (2014). In the Shadow of Basel: How Competitive Politics Bred the Crisis. Review of International Political Economy, 21(6), 1203-1239.

Thiemann, M., \& Lepoutre, J. (2017). Stitched on the Edge: Rule Evasion, Embedded Regulators, and the Evolution of Markets. American Journal of Sociology, 122(6), $1775-$

Thompson, G. F. (2016). Time, trading and algorithms in financial sector security. New Political Economy, O(0), 1-11. https://doi.org/10.1080/13563467.2016.1183116 
Turner. (2009). The Turner Review: A Regulatory Response to the Global Banking Crisis (p. 122). FSA. Retrieved from

http://www.fsa.gov.uk/pubs/other/turner_review.pdf

Underhill, G. R. D. (2015). The Emerging Post-Crisis Financial Architecture: The PathDependency of Ideational Adverse Selection. The British Journal of Politics and International Relations, 17(3), 461-493.

Weiss, H. R., \& Huault, I. (2016). Business as Usual in Financial Markets? The creation of incommensurables as institutional maintenance work. Organization Studies, 37(7), 991-1015.

Williams, J. W. (2009). Envisioning financial disorder: financial surveillance and the securities industry. Economy and Society, 38(3), 460-491.

Woll, C. (2016). Politics in the Interest of Capital: A Not-So-Organized Combat*. Politics \& Society, 44(3), 373-391.

Young, K. (2014). The politics of global financial regulation. In T. Oatley \& W. K. Winecoff (Eds.), Handbook of the International Political Economy of Monetary Relations (pp. 304-326). Cheltenham, UK and Northampton, M.A., USA: Edward Elgar Publishing.

Ziewitz, M. (2016). Governing Algorithms: Myth, Mess, and Methods. Science, Technology, \& Human Values, 41(1), 3-16.

\footnotetext{
${ }^{1}$ Commonly identified regulatory efforts contributing to the crisis include: the 1999 Gramm-Leach-Bliley Act which repealed most of the provisions in the 1933 GlassSteagall Act dividing commercial from investment banking in the United States; and the 2004 Basel II capital regulations which allowed banks to utilise their own internal models for calculating their regulatory capital.

2 These include the European Union's second Markets in Financial Instruments Directive, the German High-Frequency Trading Act, and the Commodities and Futures Trading Commission's proposed Regulation Automated Trading.

3 The interaction between global rule-making with national-level interpretation, and the desire by states to grant competitive advantages to their own financial sectors, has also
} 
been identified by the international political economy literature as a driver of regulatory arbitrage in shadow banking before the crisis (Thiemann, 2014). 